Katarzyna Jankowska, MD, PhD, https:/ / orcid.org/0000-0002-1437-050X

Department of Endocrinology

Bielanski Hospital

Center of Postgraduate Medical Education,

Warsaw

Aleksandra Kaźmierczak-Dejewska, MD, https://orcid.org/0000-0002-6412-3005

Department of Gynecology and Obestetrics

SPZZOZ in Płonsk

\title{
PCOS, Hashimoto's disease, celiac disease, endometriosis - genetically conditioned autoimmune disorder causing infertility?
}

\author{
PCOS, choroba Hashimoto, celiakia, endometrioza - zespół \\ autoimmunizacyjnych zaburzeń uwarunkowany genetycznie \\ powodujący niepłodność? ${ }^{1}$ \\ https:// doi.org/10.34766/fetr.v47i3.922
}

\begin{abstract}
Infertility is a social problem today. The causes of infertility can be both on the side of the woman and on the side of the man. One of the most common causes of infertility in women is polycystic ovary syndrome (PCOS). It has been proven that it often coexists with autoimmune thyroiditis (AIT), ie with Hashimoto's disease. In many patients with PCOS and AIT, endometriosis and celiac disease are also found. It seems that these disorders: PCOS, AIT, endometriosis and celiac disease may have a common autoimmune basis. More and more patients with infertility or recurrent miscarriages have autoimmune problems. Probably a genetic predisposition is necessary to reveal the disease.
\end{abstract}

Key words: infertility, policystic ovary syndrome, Hashimoto's disease, celiac disease, endometriosis, autoimmune basis

\begin{abstract}
Abstrakt: Niepłodność jest obecnie problemem społecznym. Przyczyny niepłodności mogą leżeć zarówno po stronie kobiety jak i po stronie mężczyzny. Jedną z najczęstszych przyczyn niepłodności u kobiet jest zespół policystycznych jajników (PCOS). Udowodniono, że często współistnieje on z autoimmunizacyjnym zapaleniem tarczycy, (AZT) czyli z chorobą Hashimoto. U wielu pacjentek z PCOS i AZT stwierdza się dodatkowo endometriozę, a nierzadko również celiakię.

Wydaje się, że te zaburzenia: PCOS, AZT, endometrioza i celiakia mogą mieć wspólne podłoże autoimmunizacyjne. Coraz więcej pacjentek z niepłodnością czy poronieniami nawracającymi ma problemy autoimmunizacyjne. Prawdopodobnie do ujawnienia choroby konieczna jest predyspozycja genetyczna.
\end{abstract}

Słowa kluczowe: niepłodność, zespół policystycznych jajników, choroba Hashimoto, celiakia, endometrioza, podłoże autoimmunologiczne

${ }^{1}$ Polska wersja: https:/ / stowarzyszeniefidesetratio.pl/Presentations0/2021-3-Jank.pdf 


\section{Introduction}

Infertility is a social problem. It is estimated that every fifth couple ( $20 \%$ of couples) have problems conceiving a child. According to WHO, after a year of ineffective efforts, infertility diagnostics should be started. Unfortunately, women often plan parenthood after the age of 35, i.e. at an advanced reproductive age which makes the prognosis even worse. With age the so-called ovarian reserve, i.e. the number of ovarian follicles, which determines the fertility of a woman (often measured by the concentration of $\mathrm{AMH}$, i.e. anti-Mullerian hormone) is getting lower. However, not only the number of follicles but also the quality is important for fertility. $\mathrm{AMH}$ is therefore not a definitive indicator of a woman's fertility potential.

Polycystic ovary syndrome is a common endocrine disorder with which infertility patients presently report. This disease may coexist with Hashimoto's disease $(22.3 \%$ compared with $8.5 \%$ of healthy patients), (Zuber-Lubecka, 2021). In the course of diagnostics (most often undertaken due to problems with getting pregnant), it often turns out that patients with PCOS and Hashimoto's disease are additionally diagnosed with endometriosis, and celiac disease also. Recently, attention has been paid to the possible common autoimmune background of these disorders. Many genes that predispose to these disorders have also been described.

Could PCO syndrome, Hashimoto's disease, endometriosis and celiac disease be an expression of the body's systemic inflammatory response? Could genes cause a larger (excessive? abnormal?) immune response? Is it possible to use immune therapy common to all of these disorders?

\section{PCOS - a heterogeneous syndrome of genetic disorders}

Polycystic ovary syndrome (PCOS) is the most common endocrinopathy, affecting 8$13 \%$ of women of reproductive age. PCOS influences the reproductive, metabolic and psychological functions of a woman. According to Rotterdam criteria, which still apply, the characteristics of polycystic ovary syndrome include hyperandrogenism (biochemical or clinical), ovulation disorders and the image of polycystic ovaries on ultrasound examination. Elevated levels of androgens result in impaired carbohydrate tolerance, insulin resistance and diabetes are common. These disorders lead to hyperglycemia, hyperlipidemia, obesity, the metabolic syndrome develops. The PCO syndrome is characterized by phenotypic diversity: there are slim patients with or without insulin resistance, as well as obese patients with or without insulin resistance. Additionally, insulin can stimulate androgen production by enhancing the theca cells' response to LH. (Cadagan, Khan, Amer, 2016), that is the reason why this disorders may be accompanied by symptoms of hyperandrogenism: acne and / or hirsutism or only biochemical hyperandrogenism. 
An increased incidence of polycystic ovary syndrome in family members of women with PCOS has been noted, which is $20-40 \%$. For comparison, in the control group it is $6-8 \%$. Interestingly, the correlation does not only concern the occurrence of PCOS in mothers of daughters with this syndrome, but also the coexistence of polycystic ovary syndrome with the metabolic syndrome in the family. 94\% of PCOS daughters' fathers are obese or overweight, and $79 \%$ presents the metabolic syndrome. The fact that girls suffering from PCOS are three times more likely to present metabolic syndrome than in the reference population after adjusting for BMI, proves that metabolic disorders in this group are not only due to excess body weight and fat, but are determined by genetic factors predisposing to the metabolic syndrome and insulin resistance regardless of the impact of BMI. (Leibel, Baumann, Kocherginsky, Rosenfield, 2006) and the epigenetic mechanisms related to androgen exposure in utero too.

In 2010 and 2015, genes of susceptibility to the occurrence of the PCO syndrome were identified. Three large genome studies of the Chinese (PCOS GWAS) and European (PCOS European GWAS) populations showed the presence of gene mutations in PCOS patients such as: LHCGR, FSHR, FSHB, THADA, INSR, FBN3, DENND1A, RAD50. (Jacha, Jakimiuk, Krzeczkowska-Sendrakowska, 2020) These genes are associated with patological functioning of the ovary, FSH and LH receptors as well as with the occurrence of insulin resistance and cardiovascular diseases. (Chen, Zhao, He, Shi, Qin, Shi, Li, You, Zhao, Liu, Liang, Zhao, Zhao, Sun, Zhang, Jiang, Zhao, Bian, Gao, Geng, Li, Zhu, Sun, Xu, Hao, Ren, Zhang, Chen, Zhang, Yang, Yan, Li, Ma, Zhao, 2011).

Further on, PCOS subtypes were distinguished, making the classification dependent on the identification of genetic factors. It is even postulated that the symptoms, genetic background, pathophysiology, and long-term consequences such as the risk of metabolic diseases are so different that they should not be considered the same disease any longer. (Dunaif \& Fauser, 2013).

The reproductive subtype (21-23\%) includes: high LH concentration, high SHBG concentration, low BMI, low insulin concentration. Women in the reproductive subtype are significantly more often carriers of one or more DENND1A variants $(P=0.03)$. This mutation affects the signaling cascade that increases the transcription of steroidogenic genes resulting in increased androgen production in the ovarian tissue cells. (Dapas, Lin, Nadkarni, Sisk, Legro, Urbanek, Hayes, Dunaif, 2020). The metabolic subtype (37-39\%) shows low LH levels, low SHBG levels, high BMI, and elevated insulin and glucose levels. However, we still recognize polycystic ovary syndrome in patients presenting both extreme phenotypes and in many patients who have mixed disorders also. 
Tab. 1. PCOS subtypes. (Dapas et al., 2020)

\begin{tabular}{|l|l|l|}
\hline PCOS subtype & reproductive & metabolic \\
\hline DENND1A mutation & + & - \\
\hline LH & $\uparrow$ & $\downarrow$ \\
\hline SHBG & $\uparrow$ & $\downarrow$ \\
\hline Glucose serum level & $\mathrm{N}$ & $\uparrow$ \\
\hline Insulin serum level & $\mathrm{N}$ & $\uparrow$ \\
\hline BMI & & $\uparrow$ \\
\hline
\end{tabular}

\section{Is PCOS an autoimmune disease?}

Due to the oligo/amennorhea type of menstrual and ovulation disorders characteristic to PCOS there is a disproportion in the levels of hormones occurring in the natural menstrual cycle in which ovulation occurs. Lack of ovulation results in a lack of the corpus luteum, which causes a deficiency of progesterone. That makes relative hyperestrogenism state. In the physiological cycle, the increase in estrogen concentration is counterbalanced by the increase in progesterone concentration. It is known that estrogens are pro-inflammatory hormones. They increase the secretion of IL-4 in Th2 lymphocytes, IL-1 in monocytes, IL-6 in T lymphocytes, and interferon- $\gamma$ in Th1 cells. During the normal menstrual cycle, the concentration of IL-6 increases during the follicular phase, which decreases with the onset of the luteal phase. The PCO syndrome lacks this balance between the effects of estrogen and progesterone. Relative hyperestrogenism contributes to the increased incidence of estrogen-dependent neoplasms in PCOS (greater incidence of breast and endometrial cancer). Thus, the very endocrine status in polycystic ovary syndrome (relative excess of estrogens) predisposes to autoimmune disorders. (Angstwurm, Gärtner, Ziegler-Heitbrock, 1997).

\section{PCOS and Hashimoto's disease - common features and autoimmune background}

In women suffering from PCOS, a more frequent coexistence of both tissue-specific antibodies, incl. anti-TPO and anti-nuclear antibodies, such as ANA or anti-ds-DNA. (Ayse, Bercem, Bilmez, Imga Nasiroglu, Mazhar Tuna, Isik, Berker, Guler, 2015). Non-specific 
markers of inflammation are also elevated in PCOS: ESR, CRP, TNF-alpha, IL-6. (Jakubowska, Bohdanowicz-Pawlak, Milewicz, 2008). The proper functioning of the mechanisms related to T-reg cells is of fundamental importance for autoimmune reactions and the process of embryo implantation. A reduced number of regulatory $\mathrm{T}$ cells has been demonstrated in endometriosis and Hashimoto's disease. In women suffering from PCOS, a reduced amount of regulatory $\mathrm{T}$ lymphocytes in the blood was also found, which, according to some researchers, is most likely due to a defective response in the IL-2 signaling pathway (defective expression of the IL-2 receptor subunit). This fact alone proves that the consequences of PCOS disorders contribute to the promotion of autoimmune diseases (Krishna, Joseph, Subramaniam, Gupta, Pillai, Laloraya, 2015).

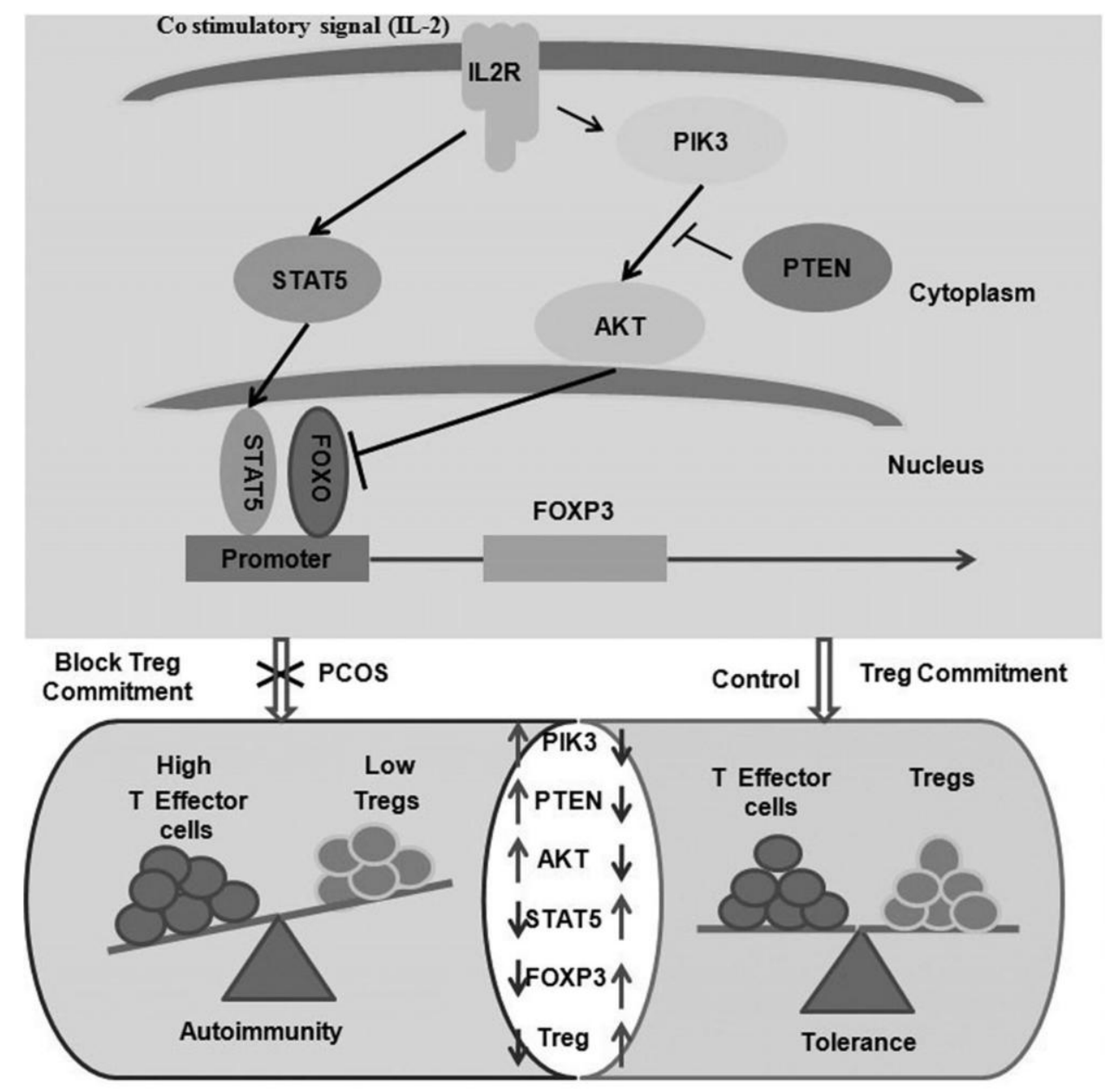

Fig. 1. Reduced Tregs in Peripheral Blood of PCOS Patients - a Consequence of Aberrant II2 Signaling

(Krishna, Joseph, Subramaniam et al. 2015)²

2 The Journal of Clinical Endocrinology \& Metabolism, Volume 100, Issue 1, 1 January 2015, Pages 282-292, https://doi.org/10.1210/jc.2014-2401. 
Additionally, the association of PCOS with Hashimoto's disease is even stronger due to for the presence of genetic polymorphisms, which predispose to the occurrence of both of these diseases. They are: FBN3-agene associated with the activity of TGF- $\beta$ and the level of Treg cells; CYP1B1- a gene involved in the metabolism of estradiol and GNRHR.

The best documented genetic link between PCOS and Hashimoto's disease is in the TGF- $\beta$ signaling pathway. Factors involved in this pathway are good candidates for susceptibility genes to both syndromes because they play a key role in the immune system, hormone regulation, inflammation, cell proliferation, tissue differentiation, apoptosis, and related metabolic consequences such as insulin resistance. In PCOS, inflammation of visceral adipose tissue resulting in the chronic release of pro-inflammatory cytokines is a major contributor to insulin resistance. Treg cells suppress the pro-inflammatory effects of autoreactive T cells. CD4 + CD25 + Foxp3 + Treg cell depletion and increased inflammation in visceral adipose tissue have been found to contribute to insulin resistance in Hashimoto's disease. Suppression of the TGF- $\beta$ signaling pathway combined with insulin resistance may lead to dysregulation of Treg cells and the promotion of autoimmunity in women with PCOS. (Zeber-Lubecka, Hennig, 2021)

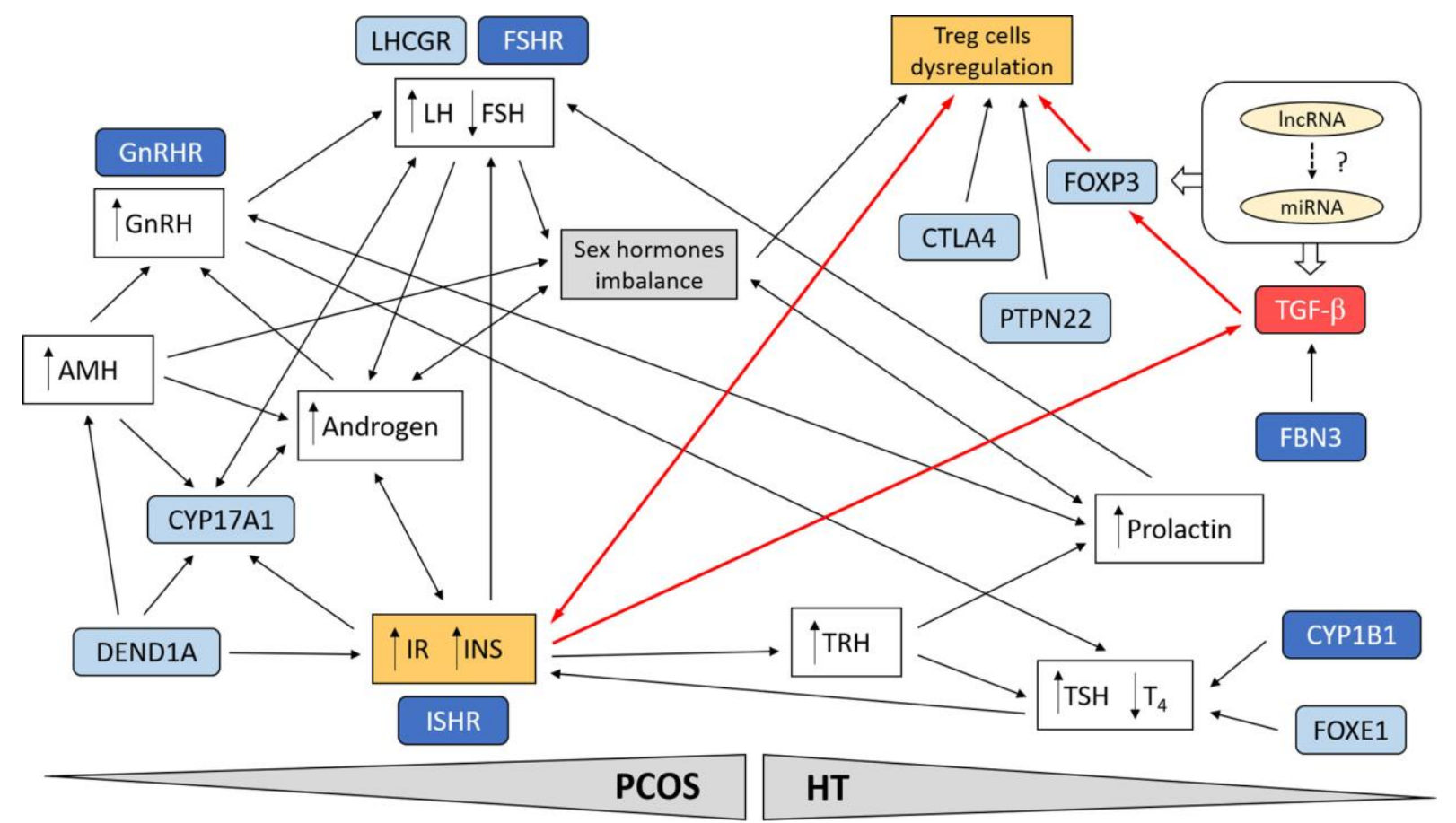

Fig. 2. Natalia Zeber-Lubecka ${ }^{1, \dagger}$ and Ewa E. Hennig 1, 2, *Genetic Susceptibility to Joint Occurrence of Polycystic Ovary Syndrome and Hashimoto's Thyroiditis: How Far Is Our Understanding? 


\section{PCOS and endometriosis - opposing or related diseases?}

The coexistence of endometriosis and PCOS seems to be much more complicated. Regarding to endocrine status, these diseases seem to be quite opposite to each other. Some authors called such diseases diametric diseases. In the pathogenesis of both these diseases, prenatal exposure to abnormal testosterone levels is postulated. The difference is that in the case of endometriosis, we talk about intrauterine and postnatal exposure to deficit testosterone concentrations, e.g. due to the action of antiandrogenic substances, and in the case of PCOS exactly the opposite - increased maternal androgen levels may result in the development of PCO in the child in the future. Another issue that connects both diseases is the malfunction of the hypothalamic-pituitary-ovary axis. In the case of PCOS, due to exposure to high concentrations of androgens, sensitivity to steroid-induced negative feedback loops is reduced, resulting in increased frequency and amplitude of gonadotropin releasing hormone $(\mathrm{GnRH})$ and luteinizing hormone $(\mathrm{LH})$ pulses with a corresponding increase in LH levels. An increased level of LH in relation to follicle stimulating hormone (FSH) causes an increased level of testosterone in the ovaries with a subsequent arrest of follicle maturation. Immature follicles release high levels of anti-Mullerian hormone (AMH), which further stimulates the release of GnRH while inhibiting the release of FSH. The ovulatory LH release is also diminished, resulting in longer or absent menstrual cycles.

In the case of decreased testosterone levels or increased levels of estradiol in prenatal life, the frequency of GnRH pulses is lower, which is reflected in the decreased LH level and increased FSH in relation to LH, the consequence is low testosterone levels in the ovaries and serum and low $\mathrm{AMH}$, and thus faster follicle maturation and therefore shorter menstrual cycles. All these disorders occur in patients with endometriosis. It might seem that in this situation polycystic ovary syndrome and endometriosis should not occur together in the same patient, but from clinical experience we know that such situations do happen. How can we explain this fact? (Dinsdale\& Crespi, 2021).

\section{Endometriosis as an autoimmune disease}

Endometriosis is a disease of unexplained etiology. Despite many theories, none has been proven. The hypothesis about the autoimmune basis of this disease seems to be the most probable. Almost every woman experiences menstrual reflux during menstrual bleeding through the fallopian tubes into the pelvic cavity. In most of them, however, these morphotic elements and fragments of the endometrium are phagocytosed by macrophages due to efficient elimination by cells of the immune system. In some women, these endometrial fragments are not recognized as foreign, the lack of a proper immune response causes them to remain active in the pelvic space, implanting into the peritoneum, intestinal 
wall, and bladder. They act like cancer. They grow out of control, sometimes resulting in changes in distant organs. The presence of endometrial tissue in the lungs and even in the brain has been described. The presence of endometriosis in the pelvic cavity can lead to adhesions, obstruction of the fallopian tubes, disorders of the bladder (dysuria) or gastrointestinal tract (dyschezia), painful sexual intercourse (dyspareunia). Painful menstruation significantly worsens the quality of life of patients, they are the reason for taking painkillers, absenteeism, and sometimes they can cause mood disorders, including depression. Advanced endometriosis is a common cause of infertility. Patients are referred to assisted reproduction (ART) procedures, but these methods often fail as well. The in vitro fertilization procedure may also end in the death of the embryo due to the lack of a proper environment for the development of pregnancy. Correct embryo implantation is possible only in a normal endometrium (impaired receptivity). The tissues of the abnormal endometrium changed in the course of endometriosis can secrete various types of endotoxins that prevent the embryo from developing.

To date, no effective method of treating endometriosis has been developed. Laparoscopic procedures are performed to remove pelvic endometriosis foci, the so-called chocolate ovarian cysts, adhesions, and to improve general fertility conditions and reduce symptoms, but endometriosis often recurs. The appearance of new foci is observed even a few months after the procedure. Endometriosis often accompanies other autoimmune diseases. It most often coexists with Hashimoto's disease and celiac disease, but other autoimmune diseases can also occur.

\section{Immune disorders in patients with endometriosis}

In the pathomechanism of endometriosis, disorders of the immune system are taken into account, because in patients with endometriosis, altered activity of the immune system cells has been found in the peripheral blood, in the peritoneal fluid and in the endometrium (Hanada, Tsuji, Nakayama, Wakinoue, Kasahara, Mori, Ogasawara, and Murakami, 2018). These disorders relate to the activity of macrophages, NK cells, cytotoxic lymphocytes and dendritic cells. Recently, attention has been paid to the role of regulatory $\mathrm{T}$ lymphocytes in the development of endometriosis (Gogacz, Winkler, Bojarska-Junak, Tabarkiewicz, Semczuk, Rechberger, and Adamiak, 2014). In patients with endometriosis, there is a decrease in the number and activity of regulatory $\mathrm{T}$ lymphocytes $(\mathrm{CD} 4+25+$ FOXp3 + ), which means that endometrial fragments are not removed, they are implanted in the peritoneum, and then spread to adjacent tissues and organs (Da Gama Coelho Riccio, Santulli, Marcellin, Abrão, Batteux, Chapron, 2018). In patients with infertility, the following diseases are often observed, such as: polycystic ovary syndrome, autoimmune thyroid disease, endometriosis, celiac disease. The common underlying causes of Hashimoto's 
disease, celiac disease, and endometriosis are understood. Most likely their coexistence is associated with altered activity of cells of the immune system. But why are endometriosis and Hashimoto's disease so common in patients with polycystic ovary syndrome?

Recent studies have shown that depletion of the androgen receptor in stem cells inhibits the function of regulatory T lymphocytes (Alawad, Altuwaijri, Aljarbu, Kryczek, Niu, Al-sobayil, Chang, Bayoumi, Zou, Rudat, and Hammad, 2015). Two conclusions can be drawn from this work: 1) stimulation (targeting) of the androgen receptor prevents the process of differentiation of CD4 + cells into Treg and 2) TGF- $\beta$ may be a further mediator of Treg activity. This finding would explain the mechanism of many autoimmune diseases. On the other hand, it is known that the TGF- $\beta$ family also includes the AMH (anti-Mullerian hormone) glycoprotein, which is produced by granulosa cells in preantral and small antral follicles in the ovaries (Pellatt, Rice, Mason, 2010). Increased AMH concentration is one of the characteristic features of the PCO syndrome (Chen, Yang, Chen, Wu, Yang, Ho, 2008). The action of $\mathrm{AMH}$ is regulated by activation of the TGF- $\beta$ receptor (Clemente, Jamin, Lugovskoy, Carmillo, Ehrenfels, Picard, Whitty, Josso, Pepinsky, and Cate, 2010). Like other members of the TGF- $\beta$ family, AMH signals are transmitted by assembling the transmembrane serine / threonine kinase receptor complex type I and type II components, resulting in phosphorylation and activation of the type I receptor kinase by the constitutively active receptor II kinase domain (Shi, Massagué 2003).

\section{Will immunomodulatory treatment be the causative treatment for PCO?}

Recently, treatment with low doses of tacrolimus in mice with PCOS has been shown to prevent hormonal and immune dysregulation of the ovaries (Albaghdadi, Feeley, Kan, 2019). Tacrolimus is a macrolide antibiotic with immunomodulatory effects. This drug inhibits T cell proliferation, IL-2 receptor expression, and the production of IL-2 and IFN-ץ. Low-dose tacrolimus therapy has been shown to improve ovarian immune function, increase endometrial progesterone receptor sensitivity, and promote uterine adaptation to pregnancy (Albaghdadi, 2021).

This is a very interesting observation, as it seems that PCOS may be caused by an innate decreased response to IL2 signaling and impaired activation of STAT5 (Krishna, 2015). Several genetic polymorphisms related to PCOS and autoimmune thyroid disease have already been described: polymorphism of the fibrillin 3 (FBN3) gene regulating the level of transforming growth factor $\beta$ (TGF $\beta$ ) and the level of regulatory $\mathrm{T}$ lymphocytes, the polymorphism of the gonadotropin releasing hormone receptor (GnRHR) gene and the polymorphism of the CYP1B1 gene estradiol hydroxylation. The increased ratio of estrogens to progesterone, high concentrations of estrogens in utero, impairing the development of the 
thymus and its function in shaping immune tolerance may predispose to the development of autoimmune disorders in PCOS.

STAT5 is necessary for Treg development because it binds to the FoxP3 promoter and regulates the expression of FoxP3 (Burchill 2007). Preclinical studies showed that thymus exposed to more estrogen had a lower capacity to produce CD4 + CD25 + Treg lymphocytes, resulting in anovulation and development of ovarian cysts (Chapman, 2009). The dysfunction of Treg in PCOS also causes low expression of the leukemia inhibitory factor (LIF) in the endometrium of women with PCOS (Kara 2019). LIF is a Treg-cytokine that plays a key role in the preparation of the endometrium for embryo implantation and postimplantation development (Stewart 1992), and thus FoxP3 + regulatory T cells determine endometrial receptivity and embryo implantation.

The differentiation of Tregs from their naive CD4 + status is determined by the activation and expression of the transcription factor FoxP3, which is mediated by the modulating cytokines TGF $\beta$, IL2 and IL15 (Guerin 2009). This critical process of differentiating CD4 $+\mathrm{T}$ cells into functioning FoxP3 + CD4 + CD25 + Treg cells may be defective in PCOS.

Disturbances can occur at any stage of this process. The target points for possible immunotherapy in PCOS may also be different.

\section{Perhaps PCOS is one of the components of the autoimmune polynocrinopathy} syndromes?

In 2020. metformin has been shown to increase the immunomodulatory potential of adipose-derived mesenchymal stem cells through STAT1 (Jang 2020). Perhaps this is why metformin is effective in PCOS - because metformin acts not only on metabolism, but also on the immune system. Insulin resistance induces the metabolic conversion of glucose to lactate through glycolysis, a process known as the "Warburg effect". Lactate causes inflammatory cells to migrate, create new blood vessels, and cause an abnormal immune response. Metformin also influences the immune response. Abnormal Treg function in PCOS causes increased synthesis of pro-inflammatory cytokines such as TNF-a, IL-6, leptin, resistin, PAI1 , TGF- $\beta$. High concentrations of these cytokines cause not only tissue insulin resistance, but also a pro-inflammatory state, endothelial dysfunction, and disorders of coagulation and fibrinolysis.

A very similar process is observed in endometriosis. Many studies have demonstrated the role of TGF- $\beta$ in the pathophysiology of endometriosis (Young, Ahmad, Duncan, \& Horne, 2017). Interestingly, TGF- $\beta$ also induces the conversion of glucose to lactate by glycolysis (Warburg effect), (Young, Brown, Maybin, Saunders, Duncan, \& Horne, 2014) - similar to insulin resistance in PCOS. 
Lactate increases cell invasion, angiogenesis and immune suppression, all key stages in the development of endometriosis. Transformation of the microenvironment in endometriosis, inhibition of TGF- $\beta$ with drugs that control immunological target points seems to be of key importance for stopping the development of endometriosis (Löffek, 2018). In patients with endometriosis, plasma levels of TGF- $\beta$ are elevated and correlate not only with progression, but also with worse clinical results in infertility treatment (Miller, Ahn, Monsanto, Khalaj, Koti, and Tayade, 2017). TGF- $\beta$ can act as a potent inducer of integrins and VEGF gene expression, thereby promoting tumor cell proliferation and tumor-induced angiogenesis.

Interestingly, inhibition of TGF- $\beta$ receptor mediated signaling by the small molecule inhibitor galunisertib (LY2157299) restores drug response in MED12 deficient cells, suggesting that MED12 deficient tumors may benefit from anti-TGF- $\beta$ therapy. (Huang, Hölzel, Knijnenburg, Schlicker, Roepman, McDermott, Garnett, Grernrum, Sun, Prahallad, Groenendijk, Mittempergher, Nijkamp, Neefjes, Salazar, ten Dijke, Uramoto, Tanaka, Beijersbergen, Wessels, Bernards, 2012). Med12 regulates ovarian steroidogenesis and uterine development. (Wang, Mittal, Castro, Rajkovic, Rajkovic, 2017). TGF- $\beta$ has been shown to inhibit $\mathrm{T}$ cell proliferation and regulate lymphocyte differentiation. For example, TGF- $\beta$ stimulates the production of regulatory T cells (Tregs) expressing CD25 and the transcription factor Foxp3 (Fontenot, Gavin, Rudensky, 2003). There is evidence of estrogen receptor (ER) and aromatase expression in ovarian stromal cells, but also in endometriosis and ovarian cancer (Rothenberger, Somasundaram, \& Stabile, 2018). Such cells include CAF, myeloid derived suppressor cells (MDSC), dendritic cells, and transformed mesothelial cells. Estradiol inhibits both cellular and humoral immunity by activating ER-a on T cells, B cells, and NK cells, with ER-a46 being the dominant isoform (Wilson, Archid, \& Reymond, 2020). Estradiol promotes the formation of a tumor microenvironment (TME) by increasing the Treg and MDSC populations, expressing programmed tumor cell death ligand (PD-L1), and inhibiting apoptosis induced by CD8 + T cells and NK cells. Estradiol reduces Th1 activity by promoting cytokine production (IL-6, IL-4, TNFa, IL-17A) and M2 TAM infiltration. The paracrine secretion of E2 and IL-6 by CAFS also contributes to this. The combination of estrogen receptor blockade and PD-L1 inhibition may be synergistic and independent of the sensitivity of tumor cells to estrogen signaling. Therapeutic strategies include direct blockade of TGF- $\beta 1$. Galunisertyb may act synergistically with anti-PD-L1 checkpoint inhibitors (e.g., nivolumab, durvalumab) in blocking TGF- $\beta 1$ suppression of host immune surveillance by Treg cells in the tumor microenvironment (Holmgaard, Schaer, Li, Castaneda, Murphy, Xu, Inigo, Dobkin, Manro, Iversen, Surguladze, Hall, Novosiadly, Benhadji, Plowman, Kalos, Driscoll, 2018). Peritoneal progression may be associated with induction of TGF- $\beta$ (RynneVidal, Au-Yeung, Jimenez-Heffernan, Perez-Lozano, Cremades-Jimeno, Barcena, CristobalGarcia, Fernandez-Chacon, Yeung, Mok, Sandoval, López -Cabrera, 2017). Many epithelial 
carcinomas that metastasize to the peritoneum overexpress TGF- $\beta$. Perhaps the use of antiPD-1 and / or anti-TGF- $\beta$ drugs will facilitate the treatment of endometriosis correlated with high levels of TGF- $\beta$, which is characteristic to other autoimmune diseases and PCOS.

The elucidation of the immune disorders in the pathogenesis of PCOS and endometriosis seems to be crucial for the causal treatment of these diseases. It will probably reduce the risk of cancer, metabolic disorders, reduce pain and improve fertility conditions. (Schadendorf, Gawlik, Haney, Ostmeier, Suter, \& Czarnetzki, 1993).

Summing up, it seems that pathophysiological use of immunotherapy is justified in endometriosis, as well as in PCOS with concomitant severe endometriosis, in cases where it is not possible to achieve pregnancy using other therapies used so far.

\section{Celiac disease and Hashimoto's disease, PCOS and endometriosis}

Hashimoto's disease, or autoimmune thyroiditis, is the most common autoimmune thyroid disease. Hashimoto's thyroiditis is characterized by the presence of anti-thyroid antibodies in the serum, such as thyroid peroxidase (TPO-Ab) and anti-thyroglobulin (TG$\mathrm{Ab})$ antibodies, which can damage thyroid cells. The association of Hashimoto's disease with many autoimmune diseases, especially celiac disease, has been explained by a common genetic factor. Similarly, some studies have shown that the incidence of Hashimoto's thyroiditis in celiac patients is $4-19 \%$ and may be related to sarcoidosis. On the other hand, elevated diagnostic markers of celiac disease include anti-gliadin antibodies (AGA) and antitissue transglutaminase (ATA) antibodies in patients with Hashimoto's thyroiditis may increase disease progression. Studies in the United States have shown a high prevalence of IgA-ATA positive titers in patients with autoimmune thyroid disease, especially Hashimoto's thyroiditis, compared to healthy subjects. In addition, several studies have investigated the relationship between anti-thyroid antibodies and anti-tissue transglutaminase or anti-gliadin antibodies in autoimmune thyroid disease. (Hadizadeh Riseh, Abbasalizad Farhang, Mobasseri, Asghari Jafarabadi, 2017).

It is believed that the coexistence of celiac disease and Hashimoto's disease is in part due to a shared genetic predisposition. The HLA-DQ2 and DQ8 haplotypes are overrepresented in many autoimmune diseases, and the inheritance of these haplotypes and their associated immune phenotype may explain the relationship. Apart from the HLA system, it has been reported that both celiac disease and autoimmune thyroiditis are associated with a gene encoding a cytotoxic T cell-associated antigen (CTLA-4), a candidate gene for thyroid susceptibility to autoimmunity (Ch'ng, Jones, Kingham, 2007).

Diagnosing and treating celiac disease in high-risk patients should be beneficial in reducing complications such as malabsorption, infertility, osteoporosis, and the development of lymphoma. Treatment of celiac disease (i.e. a gluten-free diet) also improves the 
absorption of medications for comorbid conditions such as hypothyroidism and osteoporosis. It is not known whether treating celiac disease reduces the likelihood of developing autoimmune disorders or alters their natural course. Sategna-Guidetti et al. (2001) showed that a gluten-free diet can reverse abnormalities in people with subclinical hypothyroidism, although, like Viljamaa et al. (2004), they found no correlation between the duration of gluten exposure in adults with celiac disease and the risk of the development of autoimmune thyroid disease. Ventura et al. (2000) found that diabetes and thyroid-related antibodies tended to disappear following a gluten-free diet $(11.1 \%$ at diagnosis, $5.6 \%$ after 6 months, and no diabetes-related antibodies after 12 or 24 months). and $14.4 \%, 11.1 \%, 6.6 \%$ and $2.2 \%$ for thyroid-related antibodies, respectively), while Mainardi et al. (2002) found no correlation between anti-thyroid antibodies and the introduction of a gluten-free diet. Among a cohort of 9 celiac patients with autoimmune cholestatic liver disease (seven primary biliary cirrhosis, one primary sclerosing cholangitis, and one autoimmune cholangiopathy) detected at screening, Volta and colleagues (2002) saw no clinical or biochemical improvement in cholestasis after gluten-free diet. A gluten-free diet probably needs to be started early, before autoimmune diseases take root in order to affect their course. Rami (2005) and his team, studying children with diabetes, found that asymptomatic celiac disease did not have a clear effect on metabolic control, but had a negative effect on weight gain. On the other hand, Sanchez-Albisua (2005) showed an increase in height and weight and a tendency to improve glycemic control in dietary celiac patients diagnosed in screening of children with type 1 diabetes. Acerini et al. (1998) also showed improvement in weight control. and glycemia in people treated with a gluten-free diet. These results underscore the clinical importance of celiac disease in patients with autoimmune diabetes.

\section{Summary}

Awareness of the coexistence of polycystic ovary syndrome with other autoimmune disorders is important to undertake proper diagnosis and treatment in patients trying to become pregnant. Sometimes patients undergo several ineffective assisted reproductive procedures (such as IUI or intrauterine insemination or IVF or in vitro fertilization) before they are properly diagnosed. In patients with infertility, time is very important, because a woman's older age is associated with a smaller ovarian reserve and a poorer reproductive potential. The ineffectiveness of hormonal treatment (e.g. absence of pregnancy after ovulation stimulation) in polycystic ovary syndrome may indicate another undiagnosed disorder, e.g. Hashimoto's disease or celiac disease.

Patients with celiac disease may visit specialists other than gynecologists, such as endocrinologists or gastroenterologists, with or without any symptoms. There is ample evidence of a strong association between celiac disease and other immune-mediated 
diseases, including autoimmune thyroid disorders, type 1 diabetes, primary biliary cirrhosis, inflammatory bowel disease, and autoimmune adrenal insufficiency. Some of these conditions share HLA haplotypes and non-HLA alleles, e.g., CTLA-4, which may underlie their pathogenesis. Thyroid function should be assessed in all patients with PCO, as well as celiac disease or endometriosis. Relatively cheap anti-tTG and EmA serological test kits are available for screening for celiac disease. Early diagnosis and dietary treatment reduce complications of celiac disease, such as malabsorption, osteoporosis, and the development of lymphoma, and improve drug absorption, and most importantly, improve the prognosis for pregnancy. Genetic diagnostics is also becoming more and more important, e.g. testing the TGF- $\beta$ polymorphism (Rahmioglu, 2014).

It seems that in a significant proportion of patients, PCO may be accompanied not only by Hashimoto's disease, but also by endometriosis and celiac disease. Perhaps in the future, effective immune therapies will be developed for these patients so that they can enjoy motherhood.

In recent years, there has been a rapid development of clinical immunology, and the 2018 Nobel Prize for research on anti-PD-1 drugs has brought the scientific world to a new type of therapy - immune therapy. Currently, immunotherapy is used as the first-line treatment in many neoplastic diseases (melanoma, non-small cell lung cancer, bladder cancer, kidney cancer). Therapy of the so-called with biological drugs, it is already successfully used in many autoimmune diseases, such as rheumatoid arthritis, psoriasis or multiple sclerosis. Studies using immunotherapy in endometriosis are also published: TNFa blockers (D'Antonio, 2000), recombinant IL-12 (Somigliana, 1999), interferon a (Ali, 2000), anti-PD-1 drugs (Holmgaard, 2018) and finally anti-TGF $\beta$ drugs (Löffek, 2018).

Despite the enormous progress in science, it would be best if the prevention of certain diseases was applied already in adolescence (e.g. metformin treatment, anti-inflammatory diet or physical activity in PCO syndrome). First, it is necessary to implement a causal procedure before proposing, for example, assisted reproduction (e.g. correction of hypothyroidism or a gluten-free diet in celiac disease), which is not accepted by all couples and in such cases still does not solve the problem of infertility and delays effective treatment in a situation of gradual progression. the decrease in the reproductive potential of both partners. Moreover, the education of doctors in this field is necessary. In Poland, access to many such multidisciplinary studies is payable, which is a problem for many couples.

It should also be noted that nowadays patients with PCOS often become pregnant after hormone stimulation of ovulation or after in vitro fertilization (IVF), whereas in the past such women were childless. Recently, many publications describe the meaning of the socalled fetal programming. During pregnancy, the development and maturation of, among others, the fetal organs, the brain, and the immune system. The hormonal, metabolic and immune disorders seen in a woman with PCOS can have health implications for the baby 
developing in her womb. Probably all these disorders are additionally exacerbated by the influence of endocrine disruptors. Therefore, it is necessary to educate doctors and patients themselves about proper preparation for pregnancy in order to minimize the risk of health problems in the child.

\section{Bibliography:}

Acerini, CL, Ahmed, ML, Ross, KM, Sullivan, PB, Bird, G., Dunger, DB (1998) Coeliac disease in children and adolescents with IDDM: clinical characteristics and response to gluten-free diet, Diabetic Medicine, 15, 38-44, https://doi.org/10.1002/(SICI)10969136(199801)15:1<38::AID-DIA520>3.0.CO;2-L.

Alawad, A., Altuwaijri, S., Aljarbu, A., Kryczek, I., Niu, Y., Al-sobayil, FA, Chang, C., Bayoumi, A., Zou, W., Rudat, V., Hammad, M. (2015). Depletion of androgen receptor (AR) in mesenchymal stem cells (MSCs) inhibits induction of CD4+CD25+FOX3+ regulatory $\mathrm{T}$ (Treg) cells via androgen TGF- $\beta$ interaction., Journal of Applied Biomedicine, 13 (4), 263-271, https:/ / doi.org/10.1016/j.jab.2015.06.002.

Albaghdadi, A.J.H., Feeley, C.A., Kan, F.W.K. (2019). Low-Dose Tacrolimus Prevents

Dysregulated Peri-Conceptional Ovarian and Systemic Immune Cellular Homeostasis in Subjects with PCOS., Scientific Reports, 9 [on-line],

www.nature.com/scientificreports [access: 10.07.2021],

https://doi.org/10.1038/s41598-019-42960-x.

Albaghdadi, A.J.H., Kan, F.W.K. (2021). Therapeutic Potentials of Low-Dose Tacrolimus for Aberrant Endometrial Features in Polycystic Ovary Syndrome, International Journal of Molecular Sciences, 22, 2872. https:// doi.org/10.3390/ijms22062872.

Angstwurm, M.W., Gärtner, R., Ziegler-Heitbrock, H. (1997). Cyclic plasma IL-6 levels during normal menstrual cycle, Cytokine, 9 (5), 370-374, https://doi.org/10.1006/ cyto.1996.0178.

Auer, K., Bachmayr-Heyda, A., Sukhbaatar, N., Aust, S., Schmetterer, KG, Meier, SM, Gerner, C., Grimm, C., Horvat, R., Pils, D. (2016). Role of the immune system in the peritoneal tumor spread of high grade serous ovariancancer, Oncotarget, https://doi.org/10.18632/oncotarget.11038.

Ayse, A., Bercem, A.D., Bilmez, S., Imga Nasiroglu, N., Mazhar Tuna, M.M., Isik, S., Berker, D., Guler, S. (2015). High prevalence of Hashimoto's thyroiditis in patients with polycystic ovary syndrome: does the imbalance between estradiol and progesterone play a role? Endocrine Research, 40 (4), 204-210, https://doi.org/10.3109/07435800.2015.1015730.

Burchill, M.A., Yang, J.; Vogtenhuber, C.; Blazar, B.R.; Farrar, M.A. (2007). IL-2 receptor betadependent STAT5 activation is required for the development of Foxp3+ regulatory $\mathrm{T}$ 
cells, Journal of Immunology, 178, 280-290,

https://doi.org/10.4049/jimmunol.178.1.280.

Cadagan, D., Khan, R., Amer, S., (2016). Thecal cell sensitivity to luteinizing hormone and insulin in polycystic ovarian syndrome, Reproductive Biology, 16 (1), 53-60, https:// doi.org/10.1016/j.repbio.2015.12.006.

Chapman, J.C., Min, S.H., Freeh, S.M., Michael, S.D. (2009). The estrogen-injected female mouse: New insight into the etiology of PCOS, Reproductive Biology and Endocrinology, 7,47 .

Ch'ng, C.L., Jones, M.K., Kingham, J.G. (2007). Celiac disease and autoimmune thyroid disease, Clinical Medicine $\mathcal{E}$ Research, 5 (3), 184-192, https:// doi.org/10.3121/cmr.2007.738.

Chen, M.J., Yang, W.S., Chen, C.L., Wu, M.-Y., Yang, Y.-S., Ho, H.-N. (2008). The relationship between anti-mullerian hormone, androgen and insulin resistance on the number of antral follicles in women with polycystic ovary syndrome, Human Reproduction, 23 (4), 952-957, https://doi.org/10.1093/humrep/den015.

Chen, Z.J., Zhao, H., He, L., Shi, Y., Qin Y., Shi, Y., Li, Z., You, L., Zhao, J., Liu, J., Liang, X., Zhao, X., Zhao, J., Sun, Y., Zhang, B., Jiang, H., Zhao, D., Bian, Y., Gao, X., Geng, L., Li, Y., Zhu, D., Sun, X., Xu, J.-E., Hao, C., Ren, C.-E., Zhang, Y., Chen, S., Zhang, W., Yang, A., Yan, J., Li, Y., Ma, J., Zhao, Y. (2010). Genome-wide association study identifies susceptibility loci for polycystic ovary syndrome on chromosome 2p16.3, 2p21 and 9q33.3, Nature Genetics, 43, 55-59, https:/ / doi.org/10.1038/ng.732.

Clemente, N., Jamin, SP, Lugovskoy, A., Carmillo, P., Ehrenfels, C., Picard, J.-Y., Whitty, A., Josso, N., Pepinsky, RB, Cate, RL (2010). Processing of Anti-Müllerian Hormone Regulates Receptor Activation by a Mechanism Distinct from TGF- $\beta$, Molecular Endocrinology, 24 (11), 2193-2206, https:/ / doi.org/10.1210/me.2010-0273.

Da Gama Coelho Riccio, L., Santulli, P., Marcellin, L., Abrão, MS, Batteux, F., Chapron, C. (2018). Immunology of endometriosis, Best Practice \& Research Clinical Obstetrics \& Gynaecology, 50, 39-49, https:// doi.org/10.1016/j.bpobgyn.2018.01.010.

D'Antonio, M., Martelli, F., Peano, S. et al. (2000). Ability of recombinant human TNF binding protein-1 (rh TBP-1) to inhibit the development of experimentally induced endometriosis in rats, Journal of Reproductive Immunology, 48, 81-98.

Dapas, M., Lin, FTJ, Nadkarni, G.N., Sisk, R., Legro, R.S., Urbanek, M., Hayes, M.G., Dunaif, A. (2020). Distinct subtypes of polycystic ovary syndrome with novel genetic associations: An unsupervised, phenotypic clustering analysis, PLOS Medicine 17 (6), 1-28), https://doi.org/10.1371/journal.pmed.1003132.

Dinsdale, N.L., Crespi, B.J. (2021). Endometriosis and polycystic ovary syndrome are diametric disorders, Evolutionary Applications, https://doi.org/10.1111/eva.13244. 
Dunaif, A., Fauser, B.C.J.M. (2013). Renaming PCOS - A Two-State Solution, The Journal of Clinical Endocrinology \& Metabolism, 98 (11), 4325-4328, https://doi.org/10.1210/jc.2013-2040.

Fontenot, J.D., Gavin, M.A., Rudensky, A.Y. (2003). Foxp3 programs the development and function of CD4+CD25+ regulatory T cells, Nature Immunology, 4, 330-336, https://doi.org/10.1038/ni904.

Gogacz, M., Winkler, I., Bojarska-Junak, A., Tabarkiewicz, J., Semczuk, A., Rechberger, T., Adamiak, A. (2014). T regulatory lymphocytes in patients with endometriosis, Molecular Medicine Reports, 10, 1072-1076, https:/ / doi.org/10.3892/mmr.2014.2294.

Guerin, L.R., Prins, J.R., Robertson, S.A. (2009). Regulatory T-cells and immune tolerance in pregnancy: A new target for infertility treatment? Human Reproduction, Update, 15, 517-535, https://doi.org/10.1093/humupd/dmp004.

Hadizadeh Riseh, S., Abbasalizad Farhang, M., Mobasseri, M., Asghari Jafarabadi, M. (2017). The relationship between thyroid hormones, antithyroid antibodies, anti-tissue transglutaminase and anti-gliadin antibodies in patients with hashimoto's thyroiditis., Acta Endocrinologica, 13 (2), 174-179, https:// doi.org/10.4183/aeb.2017.174.

Hanada, T., Tsuji, S., Nakayama, M., Wakinoue, S., Kasahara, K., Mori, T., Ogasawara, K., Murakami, T. (2018). Suppressive regulatory T cells and latent transforming growth factor- $\beta$-expressing macrophages are altered in the peritoneal fluid of patients with endometriosis, Reproductive Biology and Endocrinology, 16 (9),

https://doi.org/10.1186/s12958-018-0325-2.

Holmgaard, R.B., Schaer, D.A., Li, Y., Castaneda, S.P., Murphy, M.Y., Xu, X., Inigo, I., Dobkin, J., Manro, J.R., Iversen, P.W., Surguladze, D., Hall, G.E., Novosiadly, R.D., Benhadji, K.A., Plowman, D.G., Kalos, M., Driscoll, E.K. (2018). Targeting the TGF $\beta$ pathway with galunisertib, a TGF $\beta$ RI small molecule inhibitor,promotes antitumor immunity leading to durable, complete responses, as monotherapy and in combination with checkpoint blockade, Journal for ImmunoTherapy of Cancer, 6 (47), https:// doi.org/10.1186/s40425-018-0356-4.

Hu, Y., Zhang, L., Chen, H., Liu, X., Zheng, X., Shi, H., Jiang, L., Cui, D., (2019). Analysis of Regulatory T Cell Subsets and Their Expression of Helios and PD-1 in Patients with Hashimoto Thyroiditis, International Journal of Endocrinology, 5368473, 1-11, https:// doi.org/10.1155/2019/536847.

Huang, S., Hölzel, M., Knijnenburg, T., Schlicker, A., Roepman, P., McDermott, U., Garnett, M., Grernrum, W., Sun, C., Prahallad, A., Groenendijk, FH, Mittempergher, L., Nijkamp, W., Neefjes, J., Salazar, R., ten Dijke, P., Uramoto, H., Tanaka, F., Beijersbergen, RL, Wessels, LFA Bernards, R., (2021). MED12 controls the response to multiple cancer drugs through regulation of TGF- $\beta$ receptor signaling, Cell, 151 (5), 937-950, https:/ / doi.org/10.1016/j.cell.2012.10.035. 
Jacha, R., Jakimiuk, A., Krzeczkowska-Sendrakowska, M. (2020). Endokrynologia ginekologiczna. Zespót policystycznych jajników. Gdynia: Echo Kompendium.

Jang, S.G., Lee, J., Hong, S.M., Kwok, S.K., Cho, M.L., Park, S.H. (2020). Metformin enhances the immunomodulatory potential of adipose-derived mesenchymal stem cells through STAT1 in an animal model of lupus, Rheumatology, 59 (6), 1426-1438, https://doi.org/10.1093/rheumatology/kez631. PMID: 31904843.

Jakubowska, J., Bohdanowicz-Pawlak, A., Milewicz, A., Szymczak, J., Bednarek-Tupikowska, G., Demissie, M. (2008). Plasma cytokines in obese women with polycystic ovary syndrome, before and after metformin treatment, Gynecological Endocrinology 24 (7), 378-384, https:// doi.org/10.1080/09513590802128968.

Kara, M., Ozcan, S.S., Aran, T., Kara, O., Yilmaz, N. (2019). Evaluation of Endometrial Receptivity by Measuring HOXA-10, HOXA-11 and Leukemia Inhibitory Factor Expression in Patients with Polycystic Ovary Syndrome, Journal of Minimally Invasive Gynecology, 8, 118-122.

Krishna, MB, Joseph A., Subramaniam, AG, Gupta A., Pilla SM, Laloraya M., (2015). Reduced Tregs in Peripheral Blood of PCOS Patients - a Consequence of Aberrant I12 Signaling, The Journal of Clinical Endocrinology \& Metabolism, 100 (1), 282-292, https://doi.org/10.1210/jc.2014-2401.

Leibel, N.I., Baumann, E.E., Kocherginsky, M., Rosenfield, R.L. (2006). Relationship of adolescent polycystic ovary syndrome to parental metabolic syndrome, The Journal of Clinical Endocrinology \& Metabolism, 91 (4), 1275-1283, https://doi.org/10.1210/jc.2005-1707.

Löffek, S. (2018). Transforming of the Tumor Microenvironment: Implications for TGF- $\beta$ Inhibition in the Context of Immune-Checkpoint Therapy, Journal of Oncology, https://doi.org/10.1155/2018/9732939.

Mainardi, E., Montanelli, A., Dotti, M., Nano, R., Moscato, G. (2002). Thyroid-Related Autoantibodies and Celiac Disease: A Role for a Gluten-Free Diet?, Journal of Clinical Gastroenterology, 35 (3), 245-248, https://doi.org/10.1067/mpd.2000.107160. PMID: 10931424.

Miller, J.E., Ahn, S.H., Monsanto, S.P., Khalaj, K., Koti, M., Tayade, C. (2017). Implications of immune dysfunction on endometriosis associated infertility, Oncotarget, 8, 7138-7147, https://doi.org/10.18632/oncotarget.12577.

Pellatt, L., Rice, S., Mason, HD (2010). Anti-müllerian hormone and polycystic ovary syndrome: a mountain too high? Reproduction, 139 (5), 825-833, https://doi.org/10.1530/REP-09-0415.

Rahmioglu, N., Nyholt, D.R., Morris, A.P., Missmer, S.A., Montgomery, G.W., Zondervan, K.T. (2014). Genetic variants underlying risk of endometriosis: insights from meta- 
analysis of eight genome-wide association and replication datasets, Human Reproduction, Update, 20, 702-716.

Rami, B., Sumnik, Z., Schober, E., Waldhör, T., Battelino, T., Bratanic, N., Kürti, K., Lebl, J., Limbert, C., Madacsy, L., Odink, RJH., Paskova, M., Soltesz, G. (2005). Screening detected celiac disease in children with type 1 diabetes mellitus: effect on the clinical course (a case control study), Journal of Pediatric Gastroenterology and Nutrition, 41 (3), 317-321, https:/ / doi.org/10.1097/01.mpg.0000174846.67797.87.

Rothenberger, N.J., Somasundaram, A., Stabile, L.P. (2018). The Role of the Estrogen Pathway in the Tumor Microenvironment, International Journal of Molecular Science, 19 (2), 1-16, https://doi.org/10.3390/ijms19020611.

Rynne-Vidal, A., Au-Yeung, C.L., Jimenez-Heffernan, J.A., Perez-Lozano, M.L., CremadesJimeno, L., Barcena, C., Cristobal-Garcia, I., Fernandez-Chacon, C., Yeung, TL, Mok, SC, Sandoval, P., López-Cabrera, M., (2017). Mesothelial-to-mesenchymal transitionas a possible therapeutic target in peritoneal metastasis of ovarian cancer, The Journal of Pathology, 242, 140-151, https:// doi.org/10.1002/ path.4889.

Sanchez-Albisua, I., Wolf, J. , Neu, A., Geiger, H, Wäscher, I., Stern, M. (2005). Coeliac disease in children with Type 1 diabetes mellitus: the effect of the gluten-free diet, Diabetic Medicine, 22 (8), 1079-1082, https:// doi.org/10.1111/j.1464-5491.2005.01609.x.

Sategna-Guidetti, C., Volta, U., Ciacci, C., Usai, P., Carlino, A., De Franceschi, L., Camera, A., Pelli, A., Brossa, C. (2001). Prevalence of thyroid disorders in untreated adult celiac disease patients and effect of gluten withdrawal: an Italian multicenter study, The American Journal of Gastroenterology, 96 (3), 751-757, https://doi.org/10.1111/j.15720241.2001.03617.x.

Schadendorf, D., Gawlik, C., Haney, U., Ostmeier, H., Suter, L., Czarnetzki, B.M. (1993). Tumour progression and metastatic behaviour in vivo correlates with integrin expression on melanocytic tumours, The Journal of Pathology, 170 (4), 429-434, https://doi.org/10.1002/ path.1711700405.

Shi, Y., Massagué, J., (2003). Mechanisms of TGF- $\beta$ signaling from cell membrane to the nucleus, Cell, 113, 685-700.

Somigliana, E., Vigano, P., Rossi, G et al. (1999). Endometrial ability to implant in ectopic sites can be prevented by interleukin 12 in a murine model of endometriosis, Human Reproducion, 9, 14, 2944-2950.

Stewart, C.L., Kaspar, P., Brunet, L.J., Bhatt, H., Gadi, I., Kontgen, F., Abbondanzo, S.J. (1992). Blastocyst implantation depends on maternal expression of leukaemia inhibitory factor, Nature, 359, 76-79.

Ventura, A., Neri, E., Ughi, C., Leopaldi, A.,Città, A., Not, T. (2000). Gluten-dependent diabetes-related and thyroid-related autoantibodies in patients with celiac disease, The Journal of Pediatrics, 137 (2), 263-265, https:/ / doi.org/10.1067/mpd.2000.107160. 
Viljamaa, M., Kaukinen, K., Huhtala, H., Kyrönpalo, S., Rasmussen, M., Collin, P. (2004). Coeliac Disease, autoimmune diseases and gluten exposure, Scandinavian Journal of Gastroenterology, 40 (4), 437-443, https:/ / doi.org/10.1080/00365520510012181.

Volta, U., Rodrigo, L., Granito, A., Petrolini, N., Muratori, P., Muratori, L., Linares, A., Veronesi, L., Fuentes, D., Zauli, D., Bianchi, F.B. (2002). Celiac disease in autoimmune cholestatic liver disorders, The Amercian Journal of Gastroenterology, 97 (10), 2609-2613, https://doi.org/10.1111/j.1572-0241.2002.06031.x.

Wang, X., Mittal, P., Castro CA, Rajkovic G, Rajkovic A. (2017). Med12 regulates ovarian steroidogenesis, uterine development and maternal effects in the mammalian egg, Biology of Reproduction, 97 (6), 822-834, https://doi.org/10.1093/biolre/iox143.

Wilson, R.B., Archid, R., Reymond, M.A. (2020). Reprogramming of MesothelialMesenchymal Transition in Chronic Peritoneal Diseases by Estrogen Receptor Modulation and TGF- $\beta 1$ Inhibition, International Journal of Molecular Science, 21 (11), 116, https:// doi.org/10.3390/ijms21114158.

Young,V.J., Ahmad, S.F., Duncan, W.C., Horne, A.W. (2017). The role of TGF- $\beta$ in the pathophysiology of peritoneal endometriosis, Human Reproduction Update, 3 (5), 548559, https:// doi.org/10.1093/humupd/dmx016.

Young, V.J., Brown, J.K., Maybin, J., Saunders, P.T., Duncan, W.C., Horne, A.W. (2014). Transforming growth factor- $\beta$ induced Warburg-like metabolic reprogramming may underpin the development of peritoneal endometriosis, The Journal of Clinical Endocrinology E Metabolism, 99 (9), 3450-3459, https://doi.org/10.1210/jc.2014-1026.

Zeber-Lubecka, N., Hennig, E. (2021). Genetic Susceptibility to Joint Occurrence of Polycystic Ovary Syndrome and Hashimoto's Thyroiditis: How Far Is Our Understanding?, Frontiers in Immunology, https:/ / doi.org/10.3389/fimmu.2021.606620. 